REVIEW

\title{
Role of experimental approaches in marine microbial ecology*
}

\author{
Carlos M. Duarte ${ }^{1, * *}$, Josep M. Gasol ${ }^{2}$, Dolors Vaqué ${ }^{2}$ \\ 'Centro de Estudios Avanzados de Blanes, CSIC, Camí de Santa Bàrbara s/n, E-17300 Blanes, Girona, Spain \\ ${ }^{2}$ Institut de Ciències del Mar, CSIC, Paseo Juan de Borbon s/n, E-08038 Barcelona, Spain
}

\begin{abstract}
Examination of the contribution of experimental approaches to marine microbial ecology shows these appraaches to receive $34.8 \%$ of the present effort in the field. Most of the experiments focus on bacteria or marine microbial communities and generally examine the importance of trophic interactions and associated flows of carbon and nutrients in these food webs. Microbial ecologists use experimental units ranging 8 orders of magnitude in size $\left(10^{-3}\right.$ to $\left.10^{5} \mathrm{l}\right)$, with a geometric median size of $0.8 \mathrm{l}$, and an exponential decline in the number of experiments performed at increasingly larger and smaller scales. The duration of experiments is scaled linearly with the characteristic linear dimension of the experimental units, corresponding to $20 \mathrm{~d}$ for each meter in characteristic dimension. The majority $(70.3 \%)$ of the experiments performed in the past 5 yr used natural communities or organisms, particularly in mesocosm ( $>10^{3}$ l) experiments. Most $(84.5 \%)$ of the experiments are conducted under closely controlled conditions in the laboratory and involve the manipulation of particles, resources and the food web structure, usually manipulating a single factor at a time, the fraction of experiments published declining exponentially with the increase in the numbers of factors tested. A major difference between experimental marine microbial ecology and other disciplines of marine ecology is the remarkable paucity of field experiments (only $2.6 \%$ of the experiments in marine microbial ecology), where only the treatment factors are controlled, and the total absence of ecosystem experiments, which are field experiments where the treatment is applied to an entire ecosystem. Experimental approaches have played an important role in the development of marine microbial ecology, but no single experiment has had a large impact on the progress of the field, suggesting that the experiments so far conducted in marine microbial ecology have failed to provide the crucial tests of the main hypotheses needed to progress through strong inferences. The future effectiveness of experimental marine microbial ecology will be substantially enhanced through a larger allocation of efforts towards field experiments, designed to interplay with observational and comparative approaches, leading to conclusive tests of key hypotheses and paradigms through carefully designed, crucial ecosystem experiments.
\end{abstract}

KEY WORDS: Experiments - Marine microbial ecology · Design Impact - Prospect

\section{INTRODUCTION}

The general goal of marine microbial ecology is to predict and understand the abundance, distribution and role of microbial life in the sea (Redfield 1958, Jumars 1993). Marine microbial ecology studies viruses, bacteria and protists ${ }^{1}<50 \mu \mathrm{m}$ in size (e.g. Sieburth \& Estep 1985), encompassing a size range $\left(10^{-8}\right.$ to $\left.10^{-4} \mathrm{~m}\right)$ that contains half of the logarithmic size range of ma-

\footnotetext{
- This paper is dedicated to the memory of the late Robert $\mathrm{H}$. Peters, a teacher and a friend

-.E-mail: duarte@ceab.csic.es
}

rine organisms and defines the domains of interest for the practice of the discipline. Marine microbes can reach maximal densities of $10^{6}$ to $10^{12}$ cells $\mathrm{l}^{-1}$ (Duarte et al. 1987), thereby occupying nl to $\mu$ l per capita spaces, and have maximal growth rates resulting in generation

\footnotetext{
'Marine microbial ecologists have largely focussed on heterotrophic and mixotrophic organisms (traditionally considered 'consumers'), while autotrophic microbes (traditionally considered 'producers'), particularly eukaryotes, were considered to be different entities. This split, which derived from the different traditions that inspired the work of these 2 research programmes, is, however, coming to an end as more integrative approaches and concepts become dominant
} 
times shorter than $1 \mathrm{~d}$. Processes that operate at very short spatial and temporal scales are, therefore, of potential significance to marine microbial ecologists. Because physical and biological processes influence those occurring at smaller scales through well-defined transference processes (the turbulence cascade of energy transference, cf. Mackas et al. (1985) and the trophic cascade, Carpenter \& Kitchell (1992)], marine microbes are exposed to effects from physical and biological processes at a wide range of scales. As a result, the interactions between processes relevant to marine microbial ecology are particularly complex, demanding the experimental manipulation of the relevant factors in order to elucidate their significance and interactions.

Experiments test hypotheses or theories by comparing the effects of manipulating, in a statistical manner including proper replication and controls, the relevant factors with the effects predicted by the theories and hypotheses tested. Almost all of the research on marine microbial ecology could be labeled as experimental in a broad sense, since most methodologies, particularly those examining rates, require that organisms be confined and exposed to experimental treatments with parallel controls. The routine application of these techniques cannot be considered to be 'experimental', for no hypothesis is being tested in those assays (cf. Redfield 1958). Experiments manipulate marine microbes or the conditions under which they grow to test falsifiable hypotheses involving specific predictions on the outcome of the manipulations. Experimental approaches allow adequate replication and control, with the associated statistical power, and also allow the repetitive study of the same population or community and the reduction of the complexity and heterogeneity of natural ecosystems to more manageable dimensions (Gamble \& Davies 1982, Drake et al. 1996, Jafeem 1996). The efficient testing of hypotheses associated with experimental approaches has led to the assertion that only experimental approaches allow the strong inferences that are conducive to steady progress in science (Platt 1964). However, the relevance of experimental approaches to ecology has been subject to criticism (e.g. Peters 1991), which has been particularly strong for marine ecology (cf. Redfield 1958). Yet, experimental marine microbial ecology has been, and shall continue to be, a cormerstone in the progress of the field, which has experienced a recent change unparalleled by that in any other research program within marine ecology (Valiela 1995). Progress in the development of new experimental approaches is, however, lagging behind that in the development of new conceptual and methodological approaches to study marine microbial communities.

We provide here a critical assessment of the contribution of experimental approaches to marine micro- bial ecology with the goal of identifying present weaknesses and opportunities for future progress. We first examine, based on a survey of a representative sample of the published literature, the relative allocation of efforts to different subjects and approaches in marine microbial ecology. We then make a diagnosis of common flaws in experimental marine microbial ecology which is used to suggest the changes needed for an increased efficiency of experimental approaches to address key questions in marine microbial ecology.

\section{ALLOCATION OF EFFORT TO DIFFERENT SUBJECTS AND APPROACHES}

To establish the allocation of effort to different research questions within marine microbial ecology, we screened the papers published over the past $5 \mathrm{yr}$ (1990 to 1995) in a sample of the journals where the bulk of this research is published [Applied and Environmental Microbiology, Deep-Sea Research, Journal of Plankton Research, Limnology and Oceanography, Marine Ecology Progress Series, Marine Microbial Food Webs (now Aquatic Microbial Ecology) and Microbial Ecology]. Most (57\% of the papers) of the research on marine microbial ecology focuses on bacteria, followed by studies of entire microbial communities $(13.8 \%)$ or flagellates $(11.7 \%$; Fig. 1$)$. The scrutiny of the literature also revealed a growing effort directed at the examination of the ecology of marine viruses, which presently parallels that devoted to the examination of the ecology of marine ciliates 18.8 and $7.9 \%$ of the papers; Fig. 1).

The goals of recent research efforts of marine microbial ecology are varied, but most of the recently published work examines the abundance, biomass, and growth of marine microbes $(47.4 \%$ of the papers; Fig. 1). There is also a dominant interest in the elucidation of trophic interactions within microbial communities (26.6\% of the papers) and their effects on nutrient flow $(14.7 \%)$, and biogeochemical processes $(10.3 \%)$, reflecting the great impact that the reassessment of the functioning and role of marine microbial food webs (cf. Pomeroy 1974, Williams 1981, Azam et al. 1983) has had in the recent development of the field. The development of new methods in marine microbial ecology receives a moderate, albeit sustained $(10.2 \%$ of the papers), effort and there are also some emerging efforts directed at the examination of the genetic diversity within natural marine microbial assemblages $(6.1 \%$ of the papers).

Marine microbial ecology does not differ from any other subdiscipline of ecology in the array of approaches available for progress. However, observa- 
tional studies comprise a much greater share of research in marine microbial ecology $(54.4 \%$ of papers; Fig. 1) than they do in the wider field of ecology $(<20 \%$; Ives et al. 1996). This is largely a result of the delay in the development of methods to assess the abundance of the subject organisms (e.g. Hobbie et al. 1977, Porter \& Feig 1980), which was the major bottleneck for the development of marine microbial ecology (Hobbie 1993). The consolidation of a set of reliable methodologies (Kemp et al. 1993) has allowed the impressive progress made in the past 25 yr (Hobbie 1993), leading to a substantial growth of the observational base in marine microbial ecology. This will, no doubt, lead to more numerous and robust efforts to synthesize existing observations, such as comparative analyses and modeling exercises, which are still in their infancy in marine microbial ecology ( 3.9 and $6.7 \%$ of the papers, respectively; Fig. 1). The advent of syntheses in benthic microbial communities is likely to lag behind that in planktonic communities, since the study of benthic communities receives a limited $(9.2 \%$ of the papers) effort. Experimental approaches receive a larger share of the effort (34.8\% of the papers; Fig. 1) than they do in general ecological research (20\% of the papers; Ives et al. 1996). Experimental approaches are deeply rooted in marine microbial ecology, favored by the small size and short generation time of the subject organisms, which render the application of experimental approaches to microbial ecology particularly convenient (Drake et al. 1996). The large relative effort allocated to experimental approaches is also a consequence of the need to manipulate the different factors that act upon marine microbial communities in order to uncouple the complex links between processes.

\section{EXPERIMENTAL MARINE MICROBIAL ECOLOGY BY EXAMPLE}

Experimental approaches encompass the whole spectrum of goals present in marine microbial ecology, although there is a clear emphasis on trophic interactions and their effects on nutrient flow (Fig. 2). These experiments have contributed to uncovering the complexity of marine microbial food webs, providing support for the formulation of paradigms on the role of marine microbial communities (e.g. the 'microbial loop'; Pomeroy 1974, Azam et al. 1983), which have proved to be instrumental in the fast development of the field. Most of the experiments are focused on bacterial communities or microbial communities, with only a small fraction of the experimental work focusing on the largest (ciliates) and smallest (viruses) components of the marine microbial food web (Fig. 3). Experimental approaches encompass, therefore, all aspects of
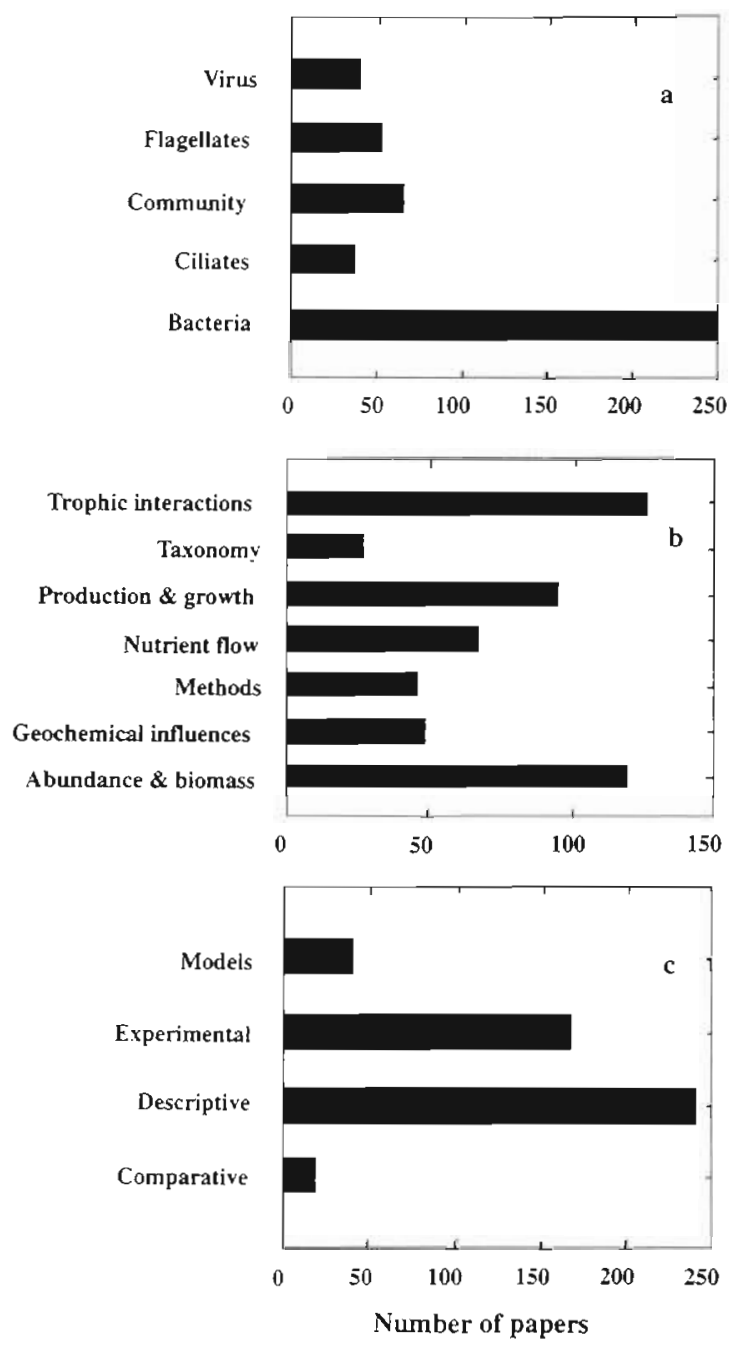

Fig. 1. Number of papers published between 1990 and 1995 in a sample of representative journals (Applied and Environmental Microbiology, Marine Ecology Progress Series, Limnology and Oceanography, Journal of Plankton Research, Microbial Ecology, Marine Microbial Food Webs, and DeepSea Research) focused on (a) the ecology of different components of marine microbial communities, (b) the examination of different aspects of the ecology of the subject organisms, and

(c) applying different approaches to achieve their goals

marine microbial ecology, but their success in testing the hypotheses or questions posed critically depends on the choices (e.g. size and duration of the experiments, origin of the organisms used, experimental layout, etc.) made when designing the experiments:

(1) Microbial ecologists use experimental units ranging 8 orders of magnitude in size $\left(10^{-3}\right.$ to $\left.10^{5} \mathrm{l}\right)$, with a geometric median size of $0.8 \mathrm{l}$, and an exponential decline in the number of experiments performed at increasingly larger and smaller scales (Fig. 4). The size of the experimental units used determines the spectra of organisms and processes that can be included in the 


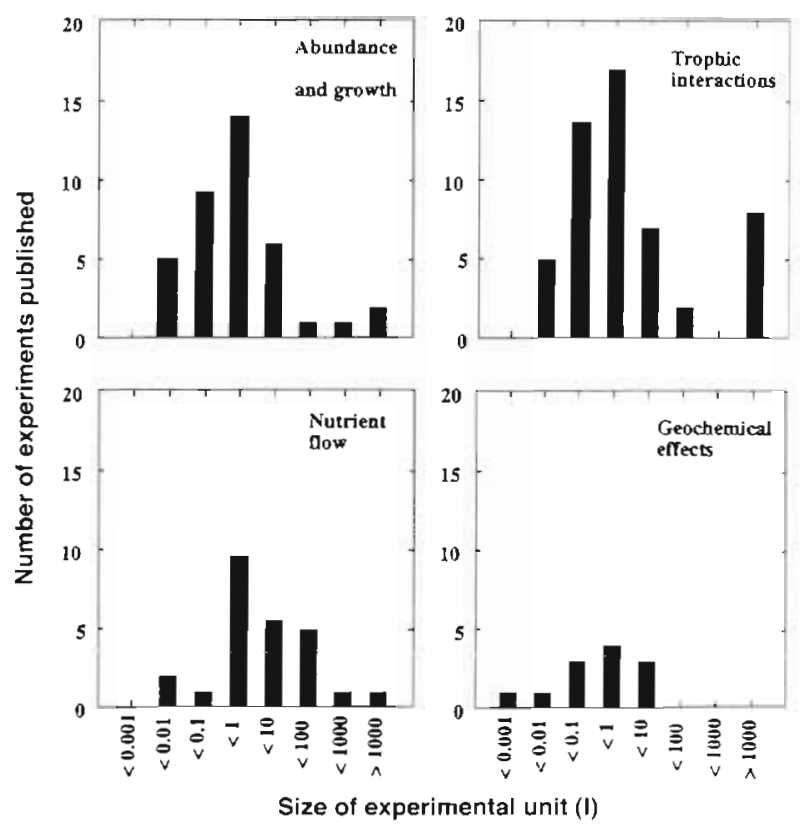

Fig. 2. Number of experimental papers on marine microbial ecology published between 1990 and 1995 in a sample of representative journals (see Fig. 1 legend for titles) using units of different sizes to examine different aspects of marine microbial ecology

experiments, as well as the cost of the units (Parsons 1982). The dominance of experimental units between 0.1 and $1 \mathrm{l}$ in marine microbial ecology should, therefore, be as much dependent on their affordability as on their suitability to the question posed. These units are generally used to test trophic interactions between subsets of organisms (i.e. particular strains or species) or responses of individual components (Fig. 2). Experimental units of intermediate size (1 to $100 \mathrm{l}$ ) are used preferably to examine the effects of microbes on fluxes of dissolved constituents, and mesocosms $\left(>10^{3}\right.$ l) are generally used to test trophic interactions in microbial communities (Fig. 2). In addition, mesocosms are also often used as 'units of opportunity' to test methodologies or run observational studies requiring repetitive sampling of the same community, but involving no treatments other than enclosure itself.

The duration of the experiment should be somewhat linked to the size of the units used, because this sets, by determining the type of organisms included, the characteristic response time scale of the experimental systems, which is usually scaled to the generation time of the largest organisms present (Beyers \& Odum 1993) The relationship between the size (as the volume, $V$, in litres) of the experimental units and the duration of the experiments ( $T$, in days) reported in the sample of the published literature on marine microbial ecology is best described by the equation (Fig. 5)

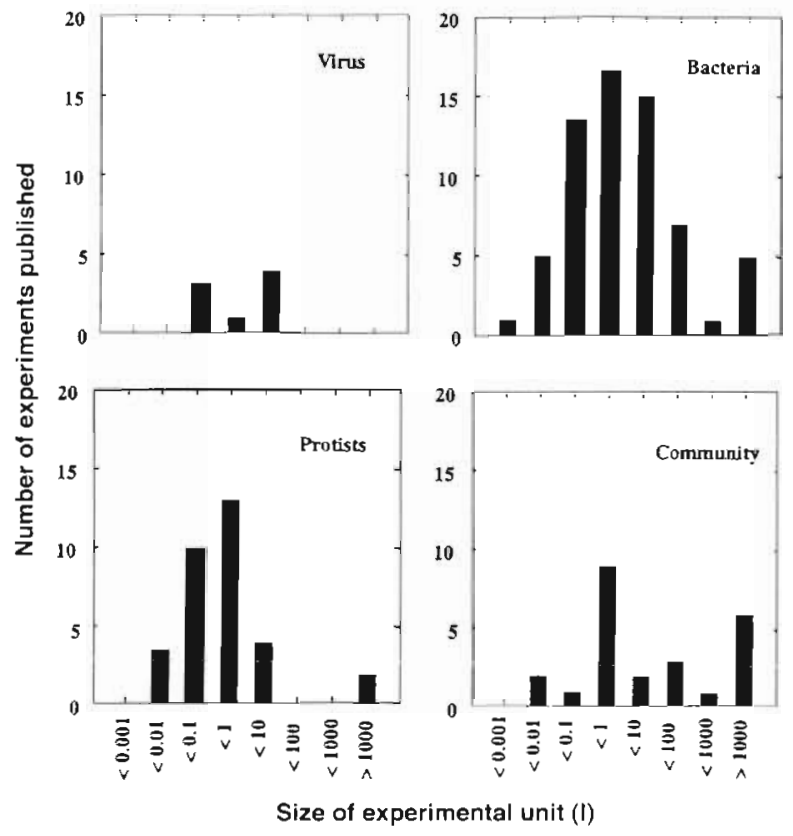

Fig. 3. Number of experimental papers on marine microbial ecology published between 1990 and 1995 in a sample of representative journals (see Fig. 1 legend for titles) using units of different sizes to examine different components of marine microbial communities

$$
T=1.92 V^{029}
$$

which indicates that, on the average, the duration of experiments is scaled as the $1 / 3$ power of the volume of the experimental units. This implies a linear scaling between the duration of the experiment and the characteristic linear dimension of the experimental units (as the equivalent spherical diameter), roughly corresponding to $20 \mathrm{~d}$ for each $1 \mathrm{~m}$ in characteristic dimension. Since this average relationship is based on

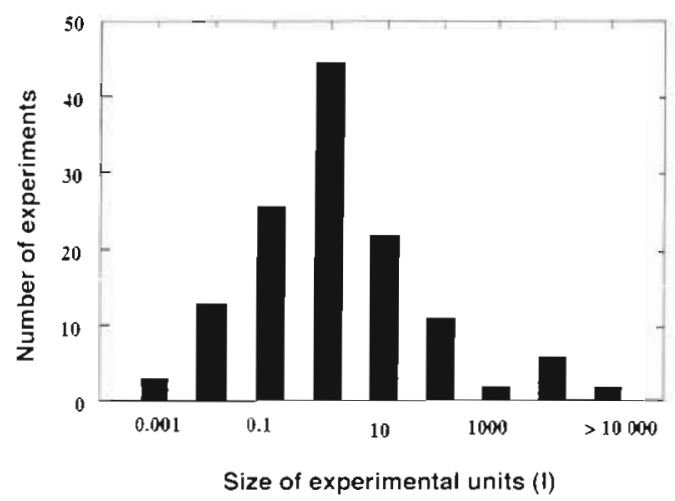

Fig. 4. Size distribution of the experimental units used in experimental papers on marine microbial ecology published between 1990 and 1995 in a sample of representative journals (see Fig. 1 legend for titles) 


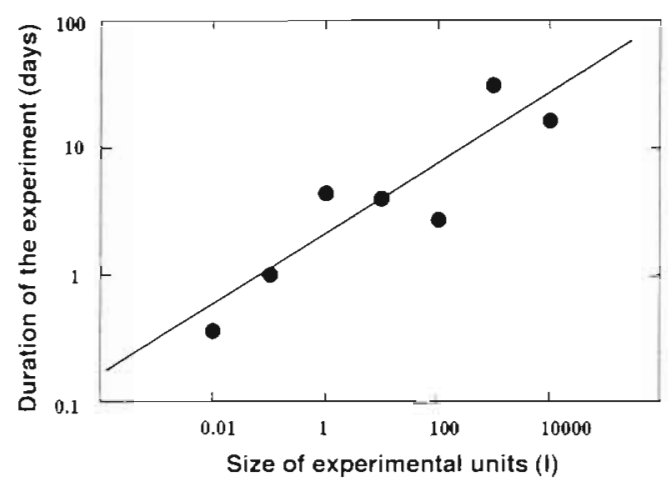

Fig. 5. Relationship between the size and duration of the experiments reported in papers on marine microbial ecology published between 1990 and 1995 in a sample of representative journals (see Fig. 1 legend for titles)

examination of the experiments that were successful enough to merit publication, it can serve as a rule of thumb for the design of experiments. However, small systems are sometimes used in exceedingly long experiments and, conversely, units as large as $100 \mathrm{l}$ are sometimes used to run experiments lasting only a few hours. An inappropriate scaling between the size and duration of experiments may generate artifacts by excluding important features of the ecosystems or including unwanted effects (Carpenter \& Kitchell 1992, Carpenter 1996). Experiments too long for the size of the experimental unit may confound the responses tested by including stochastic changes in the communities enclosed, the development of microheterogeneity and a dominance of wall effects. Experiments too short for the experimental units used may lead to error by confounding transient changes with the response tested.

The experimental units commonly used in marine microbial ecology are closed to immigration and emigration and often disrupt the continuity between the organisms and their environment. The confinement and isolation of the organisms often have effects as large or larger than those of the treatments under examination (Mullin 1982). In addition, enclosure removes some of the components of the system and also some of its variability. As a consequence, many of the results obtained depend on contingencies derived from the initial conditions of the water sample enclosed, leading to low reproducibility of the experiments.

(2) The majority (70.3\%) of the experiments performed in the past 5 yr used natural communities or organisms. The nature of the communities used differed, depending on the size of the experimental units, with mesocosm ( $>10^{3}$ l units) experiments predominantly using natural communities, while experiments with units in the range of 1 to 101 frequently used 'cul- tured' communities (Fig. 6). The use of cultured organisms allows better replicability and control of the experiments at the risk of a loss in relevance. Extrapolation of the responses observed on a particular organism or cultured assemblage of organisms to natural organisms or communities may lead to unsupported expectations on the functioning of marine microbial communities

(3) An appropriate design, involving proper selection and combination of treatments and levels, and adequate replication and controls, is crucial for the success of the experiment. The nature of the treatments applied in experimental marine microbial ecology is quite broad (Fig. 7). The treatments most commonly applied involve the manipulation of particles (particle exclusion or addition), resources (organic and inorganic nutrient addition), and food-web structure (predator or prey inclusion or exclusion). The examination of the response to experimentally applied stresses (chemical or physical) also received significant atten-

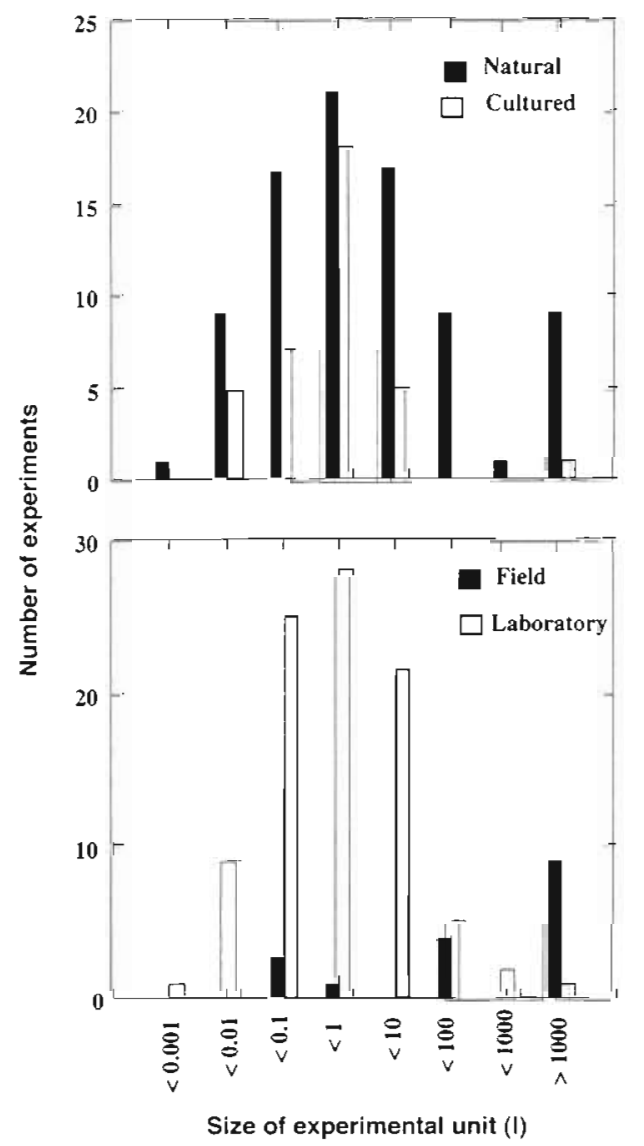

Fig. 6. Number of experimental papers on marine microbial ecology published between 1990 and 1995 in a sample of representative journals (see Fig. 1 legend for titles) using units of different sizes enclosing natural or cultured communities and conducted in the laboratory or the field 


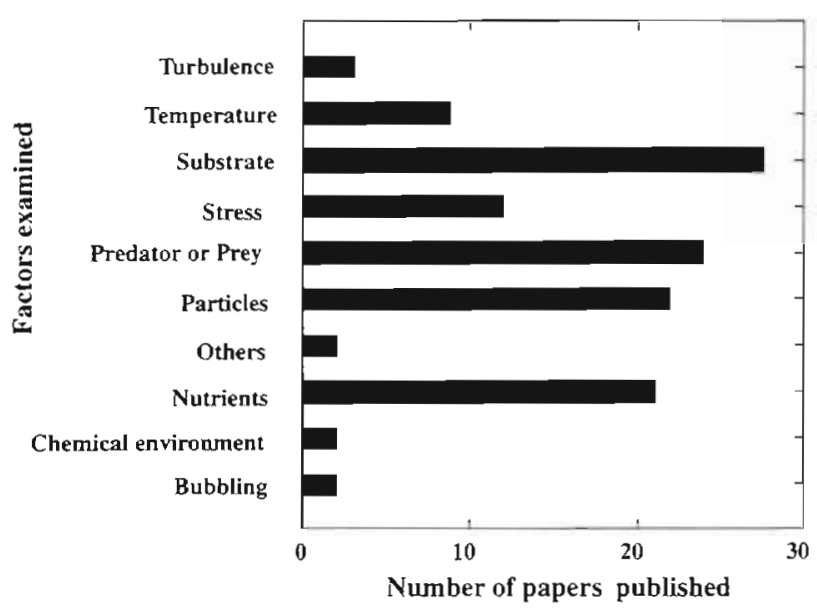

Fig. 7. Number of expenments testung the effects of ciifter ent treatment variables in the papers on marine microbial ecology published between 1990 and 1995 in a sample of representative journals (see Fig. 1 legend for titles)

tion, while other factors tested (temperature, kinetic energy, etc.) represent a minor fraction of the analyses (Fig. 7). The broad array of processes influencing marine microbes and the complexity of the trophic interactions among them suggest that multifactorial experiments should play a dominant role in experimental marine microbial ecology. This is, however, not the case, for most experiments involve the manipulation of a single factor (cf. Pace 1991) and the fraction of experiments conducted declines exponentially as the number of factors tested increases (Fig. 8). The simple nature of most experimental marine microbial ecology is further illustrated by the observation that singlefactor experiments only rarely involve the application

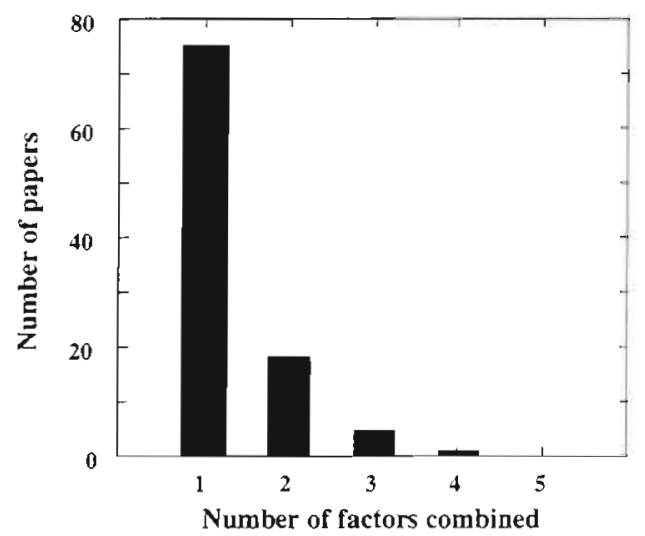

Fig. 8. Relationship between the number of treatments simultaneously tested and the number of papers on experiments in marine microbial ecology published between 1990 and 1995 in a sample of representative journals (see Fig. 1 legend for titles) of different levels of the treatment variable, and that the examination of multiple factors is often achieved through a series of single-factor experiments, rather than a multifactorial design. Even worse, experiments often lack proper replication of the treatments, particularly those using large units, and the description of the experimental design often lacks detail on critical aspects, such as the level of replication and the size and duration of the experiments.

(4) The extent of control over the experimental conditions used in marine microbial ecology also varies considerably. The vast majority of the experiments ( $84.5 \%$ in our sample of the literature) are conducted in the laboratory, where all conditions can be closely controlled (Fig. 6). Some of the experiments conducted in large units (>100 l and larger) are run outdoors (often on deck of research vessels) and most of the mesocosm experiments use bags suspended in the water, where temperature and irradiance may be closer to those experienced by natural communities and construction costs are minimized. A major difference with experimental approaches in other disciplines of marine ecology is the almost absolute lack of field experiments, where only the treatment factors are controlled, and the total absence of ecosystem experiments, which are field experiments where the treatment is applied to entire ecosystems, in marine microbial ecology. The progress of ecology has involved the increasing replacement of laboratory experiments by field experiments in an attempt to increase their relevance. Field experiments in ecology have grown from $2-4 \%$ of the published papers in the 1950 s to $25-35 \%$ in the late 1980 s (Hairstron 1989). In contrast, field experiments still represent a minor fraction $(2.6 \%)$ of the experiments in marine microbial ecology, similar to that characteristic of the ecology practiced in the $1950 \mathrm{~s}$. We computed, in our sample of the recent literature, only 17 field experiments, of which 13 represent mesocosm experiments. Mesocosm experiments represent an attempt to bridge the gap between experimental and field studies in marine ecology (e.g. Parsons 1982). Yet, they enclose a fraction of the ecosystem, disrupting chemical and biological continuity and generating artifacts derived, for instance, from wall effects and reduced mixing. Attempts at solving the artificial aspects of mesocosms can often be as unnatural as the problem itself (Mullin 1982). If the goal of mesocosm experiments was to test the effects of enclosing a fraction of the ecosystem by comparing the changes in the properties of interest within the mesocosms with those in the open ecosystem, then they could possibly be considered field - albeit trivial experiments. However, this is not the case and many properties other than the treatment itself are changed in the process of enclosing the communities in the 
mesocosms, rendering the extrapolation of the results to the adjacent waters cumbersome. As a result, mesocosm experiments in general cannot be appropriately considered field experiments, but rather experiments conducted in the field.

\section{A DIAGNOSIS OF COMMON FLAWS}

The profile of experimental marine ecology derived from our review of the published literature helps identify some widespread weaknesses:

(1) The vast majority of experiments on marine microbial ecology are conducted in the laboratory, where all conditions are carefully controlled, and the number of treatment variables is typically low. Experiments conducted under tightly controlled conditions are reductionistic and unnatural to some extent (cf. Redfield 1958), because the tight control exerted increases the likelihood of observing significant responses of treatments that may turn out to have no discernible significance in nature. As a consequence, experiments run under closely controlled conditions carry large uncertainty when extrapolated to nature, so that their heuristic value is not paralleled by predictive power.

(2) The review of the recently published literature stresses the simplicity of experimental designs (unifactorial with few or no replicates) as a salient feature of marine microbial ecology. This simplicity cannot be attributed to the increase in cost with increasing experimental complexity, since the experiments run in expensive mesocosms are often more elaborate than those conducted in inexpensive laboratory microcosms. The primitive design of most of the experiments in marine microbial ecology may reflect, therefore, a lack of interest in the elucidation of interactions among factors, which does require multifactorial experiments.

(3) Experiments in marine microbial ecology often miss the needs and opportunities present in the field. For instance, although trophic interactions between marine microbes often involve processes and interactions at the microscale, experimental examination of these interactions at the relevant scales (e.g. Müller-Niklas et al. 1996) is virtually absent from the published literature. Processes occurring at these scales have been addressed mostly through speculation (Azam et al. 1983, Azam \& Ammerman 1984) supported by a reduced set of observational studies (e.g. Duarte \& Vaqué 1992, Müller-Niklas et al. 1996), and a few (untested) models built over a very thin empirical basis (e.g. Jackson 1987,1989, Bowen et al. 1993). Yet, current understanding of microbial food webs is firmly grounded on assumptions about the processes occurring at these small scales (Azam et al. 1983, Azam \& Ammerman 1984, Jackson 1987), which suggests that the experimental evaluation of these processes would represent a critical test of the paradigm (Platt 1964).

(4) One of the greatest problems of experimental marine microbial ecology, which partially results from the problems stated above, is that of how to extrapolate results derived from experiments, particularly those conducted in small units, to nature (cf. Carpenter \& Kitchell 1992, Carpenter 1996). Scaling of results from microcosms, the dominant experimental scale in marine microbial ecology, is rarely verified, but the few data available indicate that the smaller the size of the experimental units, the greater the deviations from the ecosystem responses (Beyers \& Odum 1993). For instance, Kroer \& Coffin (1992) report that rates of microbial processes are consistently reduced in microcosms as a result of disruption of critical processes, and Marrasé et al. (1992) report effects of the size of the experimental units on estimates of grazing rates on bacterioplankton. Further evidence of the difficulties in extrapolating experimental results derives from the observation that inferences drawn from similar experiments at different experimental scales (i.e. bottles to bags) are often inconsistent (Pace \& Cole 1994).

The common deficiencies outlined above may explain the limited impact of experimental marine microbial ecology (Fig. 9). Examination of the 10 papers in marine microbial ecology most cited over the period 1990 to 1995 revealed that papers reporting methods of examining the abundance of marine microbes, bacteria in particular, have had the greatest influence in the field, followed by conceptual models of the role of marine microbes and the interactions occurring within the microbial food web (Fig. 9). While these methodological and conceptual developments largely rest on the basis of experiments (e.g. $27 \%$ of the papers cited in Azam et al. 1983 are experimental), the fact is that no single experimental test has provided the crucial test of key hypotheses needed to progress through strong inferences (Platt 1964). This is in contrast with other domains of marine (e.g. Cullen 1995) and aquatic (Schindler \& Fee 1974, Schindler et al. 1985, Benndorf 1990, Carpenter 1990, Carpenter \& Kitchell 1993, Pace \& Cole 1996) ecology, or general ecological theory (Naeem et al. 1994), where crucial, large-scale experiments testing key concepts have been successfully completed.

\section{PROSPECTS: TOWARDS A STRONG EXPERIMENTAL PROGRAM IN MARINE MICROBIAL ECOLOGY}

Marine microbial ecology has grown exponentially over the past 25 yr (Valiela 1995), building over the development of an appropriate set of methods and a 


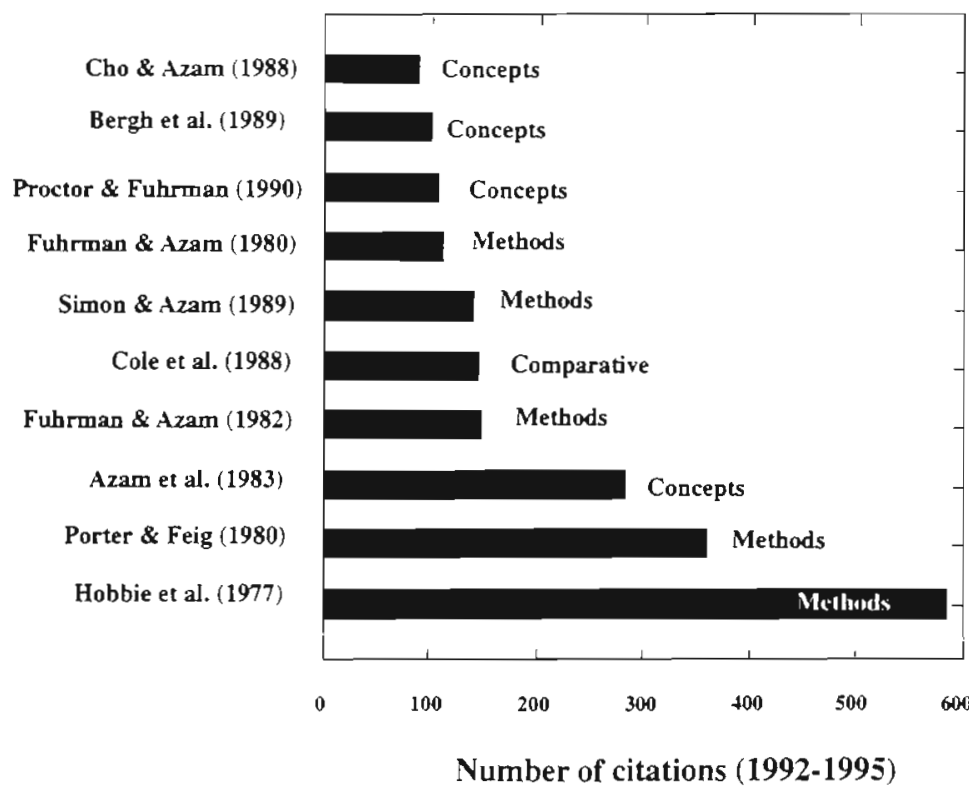

Fig. 9. The 10 most influential papers in present marine microbial ecology. The list represents the number of citations these papers received over the period 1992 to 1995

robust paradigm of the functioning of marine microbial communities (Pomeroy 1974, Williams 1981, Azam et al. 1983). This progress has been achieved largely through efforts, often involving small-scale laboratory experiments, towards the elucidation of the 'how' (e.g. 'how' to estimate organismal abundance and activity, 'how' do microbial organisms interact with each other and with metazoans, etc.). While these studies have helped to define the possible interactions occurring within the microbial food web, they were insufficient to establish their relative importance in nature. The development of marine microbial ecology as a predictive science must be achieved through a shift of efforts to establish 'how much', allowing elucidation of the probable from the possible (Peters 1991). This is, however, not easily derived from observational studies alone, for inferences derived from the comparison of rates are 'weak' (Platt 1964) and often misleading (Pace 1991). The effective study of the quantitative importance of different interactions within microbial communities requires the use of comparative and experimental studies (Pace 1991). Although comparative analyses are certainly useful, the mechanistic inferences derived from them are always hypothetical and must be tested experimentally. We, therefore, argue that steady progress in marine microbial ecology requires the use of experimental tests carefully designed to allow the unambiguous rejection of hypotheses (Platt 1964). A strong experimental program in marine microbial ecology must strive to provide crucial tests of key hypotheses and paradigms. These tests are unlikely to be derived from laboratory experiments, for extending the number of factors and levels tested in an attempt to account for the multiple interactions between the processes influencing marine microbes will only lead to exceedingly cumbersome experiments, difficult to implement and interpret. Field experiments may partially overcome these difficulties, for the significance of the treatments applied is assessed in the presence of natural variability and interactions, so that results derived from even simple experimental designs may provide conclusive tests when conducted in the field. The hypotheses and paradigms surviving the test of field experiments must be eventually subject, if at all possible, to testing at the relevant scale of the ecosystem, leading to solid establishment of theory.

The paucity of field experiments in marine microbial ecology is probably a consequence of the perceived operational difficulties associated with the design of these experiments, which may be overcome by an increased awareness of opportunities to conduct simple field experiments. For instance, dialysis bags suspended in situ have been used to derive in situ growth rates of bacterioplankton (Herndl et al. 1993) and provide, in combination with the selective filtration or concentration of different size fractions, analogues of 'cage experiments', which have potential as tools to design field experiments to test trophic interactions between planktonic microbes (Herndl et al. 1993, del Giorgio et al. 1996). Although the in situ manipulation of the growth conditions of benthic microbial communities may be relatively easier, it has been only rarely attempted (e.g. López et al. 1997) This indicates that operational difficulties alone do not suffice to account for the paucity of field experiments in marine microbial ecology.

The design of the crucial field experiments needed to test key paradigms (e.g. the importance of trophic interactions within microbial communities in the control of biogeochemical fluxes) is far from simple. The factorial designs required to simultaneously test the importance of the large number of relevant interactions would require extraordinarily cumbersome experiments. This difficulty, common to all fields of ecology, has been overcome through the development of ecosystem experiments, which have provided the conclusive tests needed to resolve controversies in ecology (Likens 1985). They have been effectively used in aquatic ecology to test the role of mutrients in eutrophication (Schindler \& Fee 1974), the effects of acid rain 
(Schindler et al. 1985) and complex trophic interactions (Benndorf 1990, Carpenter 1990, Carpenter \& Kitchell 1993, Pace \& Cole 1996) in freshwaters. Ecosystem experiments often represent perturbation experiments, which frequently lack appropriate controls and replication (Stewart-Oaten et al. 1992). This weakness introduces statistical uncertainty into the results, but has not prevented ecosystem experiments from providing the most conclusive tests for an array of problems in aquatic ecology. Although it can be argued that ecosystem-level experiments are easier to conduct in more confined freshwaters than in the more open marine ecosystems, this argument does not appear to suffice to account for the absolute absence of these experiments in marine microbial ecology. Wholesystem experiments are extraordinarily demanding in resources, which imposes strict limits on their execution in marine ecology, but have been recently performed in the open ocean. The combination of lagrangian approaches, which have proved most useful to study marine microbial communities in situ (e.g. Carlucci et al. 1984, Carpenter \& Campbell 1988), with experimental manipulations is an effective approach to test key hypotheses. As an example, the IRONEX experiments tested the hypothesis that iron limitation can control the biomass and productivity of phytoplankton in the open sea (cf. Cullen 1995). Yet, the opportunities offered by the IRONEX experiments to examine the responses of microbial heterotrophs to ecosystem-level iron additions were apparently missed, despite growing evidence that microbial heterotrophs may play a major role in the oceanic iron cycling (e.g. Twiss \& Campbell 1995, Barbeau et al. 1996, Tortell et al. 1996). It appears, however, that microbial heterotrophs have received due attention in the IRONEX II experiment (Cochlan \& Kudela 1996). The resources required to conduct ecosystem experiments in small coastal lagoons and sheltered bays are more modest and, yet, none have been attempted to our knowledge. We must, therefore, conclude that the limitation of resources cannot be the reason for the lack of ecosystem experiments in marine microbial ecology.

Realization of the absence of solid reasons to account for the paucity of field experiments and the lack of ecosystem experiments must lead to creative efforts to design simple, albeit innovative, such experiments to foster progress in marine microbial ecology. While we contend that experimental approaches must play a key role in the future development of marine microbial ecology, they must do so based on the efficient interplay with other approaches. Descriptive, observational studies are needed to generate the empirical basis required to formulate relevant hypotheses and conduct comparative analyses. These, in turn, provide useful rules and generalizations that lead to predictions that must be tested experimentally. These tests may involve, in the initial steps, laboratory experiments, but they must eventually consider field experiments leading to crucial ecosystem-level experiments. Integration of these approaches can be made explicit through the design of multiple, coordinated experiments along relevant gradients. For instance, Kirchman et al. (1990) measured the effect of glucose additions on bacterial $\mathrm{NH}_{4}$ uptake along different stations on a cruise; Shiah \& Ducklow (1994) combined repeated experiments involving substrate additions and temperature manipulations at 4 sites to test their importance in controlling bacterial abundance in Chesapeake Bay; Christian \& Karl (1995) combined experiments on the temperature dependence of ectoenzymatic activity from different oceanic provinces; and López et al. (1997) conducted experimental nutrient additions to a range of benthic bacterial communities to test the hypothesis of nutrient limitation of benthic bacterial activity in the NW Mediterranean littoral. Such coordinated experiments, which could be labeled 'meta-experiments', represent the comparative analyses of experiments, and combine, therefore, the comparative, experimental, and observational approaches. Meta-experiments are not yet articulated as a coherent approach in marine microbial ecology, but hold the potential to increase the relevance of experimental marine microbial ecology by allowing the scaling up of experimental results obtained at small scales into a larger context and, when planned along well-defined gradients, the elucidation of the factors that affect the responses tested. The growing opportunities for international research collaboration also provide an optimal platform for the design of meta-experiments across broad gradients.

\section{CONCLUSION}

In summary, experimental approaches receive a much greater share of efforts in marine microbial ecology than they do in the broader field of ecology. However, the large efforts devoted to experimental approaches appear to have yielded only a modest influence on the progress of marine microbial ecology. The most important limitations behind the unsatisfactory contribution of experimental approaches to the progress of marine microbial ecology are the simple nature of the experimental designs, the absence of experimental tests of some key hypotheses and difficulties in extrapolating the results to nature derived from the paucity of field experiments and the absolute absence of ecosystem experiments. This is in contrast with the growing importance of field experiments with careful, complex designs that allow elucidation of interactions, and the use of ecosystem experiments to 
provide the crucial test of key hypotheses, which characterize successful experimental efforts in modern ecology. The effectiveness of future efforts in experimental marine microbial ecology will be substantially enhanced through a greater concentration on field experiments, designed to interplay with observational and comparative approaches and leading to conclusive tests of key hypotheses and paradigms through carefully designed crucial ecosystem experiments.

Acknowledgements. This research was funded by the European Commission under the MAST programme (contract MAS3-CT96-0045) and by the Spanish Commission of Science and Technology (CICYT project AMB94-0746). We gratefully acknowledge the Comisó Interministerial de Ciencia i Tecnologia (CIRIT, grant GRQ93-80-42) for their support We thank Frede Thingstad and an anonymous reviewer for helpful critical advice. This is ELOISE publication number 15 .

\section{LITERATURE CITED}

Azam F, Ammerman JW (1984) Cycling of organic matter by bacterioplankton in pelagic marine ecosystems: microenvironmental considerations. In: Fasham MDR (ed) Flows of energy and materials in marine ecosystems. NATO Conf Ser 4, Mar Sci Vol 13, Plenum, New York, p 345-360

Azam F, Fenchel T, Field JG, Gray JS, Meyer-Reil LA, Thingstad $F$ (1983) The ecological role of water-column microbes in the sea. Mar Ecol Prog Ser 1.0:257-263

Barbeau K, Moffett JW, Caron DA, Croot PL, Erdner DL (1996) Role of protozoan grazing in relieving iron limitation of phytoplankton. Nature 380:61-63

Benndorf J (1990) Conditions for effective biomanipulation: conclusions derived from whole-lake experiments in Europe. Hydrobiologia 200/201:187-203

Bergh $\varnothing$, Børsheim KY, Bratbak G, Heldal M (1989) High abundance of viruses found in aquatic environments. Nature 340:467-468

Beyers RJ, Odum HT (1993) Ecological microcosms. SpringerVerlag, New York

Bowen JD, Stolzenbach KD, Chisholm SW (1993) Simulating bacterial clustering around phytoplankton cells in a turbulent ocean. Limnol Oceanogr 38:36-51

Carlucci AF, Craven DB, Henrichs SM (1984) Diel production and microheterotrophic utilization of dissolved free amino acids in waters off Southern California. Appl Environ Microbiol 48:165-170

Carpenter EJ, Campbell L (1988) Diel patterns of cell division and growth rates of Synechococcus spp. in Long Island Sound. Mar Ecol Prog Ser 47:179-183

Carpenter SR (1990) Large-scale perturbations: opportunities for innovation. Ecology 71:2038-2043

Carpenter SR (1996) Microcosm experiments have limited relevance for community and ecosystem ecology. Ecology $77.677-680$

Carpenter SR, Kitchell JF (1992) Trophic cascade and biomanipulation: interface of research and management. Limnol Oceanogr 37:208-213

Carpenter SR, Kitchell JF (1993) The trophic cascade in lakes. Cambridge Univ Press, London

Cho BC, Azam F (1988) Major role of bacteria in biogeochemical fluxes in the ocean's interior. Nature 332:441-443
Christian JR, Karl DM (1995) Bacterial ectoenzymes in marine waters: activity ratios and temperature responses in three oceanic provinces. Limnol Oceanogr 40:1042-1049

Cochlan W, Kudela R (1996) Inorganic and organic nitrogen uptake dynamics in the equatorial Pacific during Iron $E x$ II. San Diego ASLO meeting, abstract book American Geophysical Union, Washington, DC, p 177

Cole JJ, Findlay S, Pace ML (1988) Bacterial production in fresh and saltwater ecosystems: a cross-system overview. Mar Ecol Prog Ser 43:1-10

Cullen JJ (1995) Status of the iron hypothesis after the OpenOcean Enrichment Experiment. Limnol Oceanogr 40: $1336-1343$

del Giorgio PA, Gasol JM, Vaqué D, Mura P, Agustí S, Duarte CM (1996) Protistan control of the proportion of metabolically active cells in coastal marine bacterioplankton. Limnol Oceanogr 41:1169-1179

Drake JA, Huxel GR, Hewitt CL (1996) Microcosms as models for generating and testing community theory. Ecology 77 : $670-677$

Duarte CM, Agustí S, Peters RH (1987) An upper limit to the abundance of aquatic organisms. Oecologia 74 : $272-276$

Duarte CM, Vaqué D (1992) The scale dependence of bacterial patchiness. Mar Ecol Prog Ser 84:95-100

Fuhrman JA, Azam F (1980) Bacterioplankton secondary production estimates for coastal waters of British Columbia, Antarctica and California. Appl Environ Microbiol 39: $1085-1095$

Fuhrman JA, Azam F (1982) Thymidine incorporation as a measure of heterotrophic bacterioplankton production in marine surface waters: evaluation and field results. Mar Biol 66:109-120

Gamble JG, Davies JM (1982) Application of enclosures to the study of marine pelagic systems. In: Grice GD, Reeve MR (eds) Marine mesocosms. Biological and chemical research in experimental enclosures. Springer-Verlag, New York, p 25-48

Hairstron NG Sr (1989) Ecological experiments. Purpose, design, and execution. Cambridge Univ Press, New York

Herndl GJ, Kaltenböck E, Müller-Niklas G (1993) Dialysis bags incubated as a nonradiolabeling technique to estimate bacterioplankton production in situ. In: Kemp PF, Sherr BF, Sherr EB, Cole JJ (eds) Handbook of methods in aquatic microbial ecology. Lewis Publishers, Boca Raton, FL, p 553-556

Hobbie JE (1993) Introduction. In: Kemp PF, Sherr BF, Sherr $E B$, Cole JJ (eds) Handbook of methods in aquatic microbial ecology. Lewis Publishers, Boca Raton, FL, p 1-5

Hobbie JE, Daley RJ, Jasper S (1977) Use of Nuclepore filters for counting bacteria by fluorescence microscopy. Appl Environ Microbiol 33:1225-1228

Ives AR, Foufopoulos J, Klopper ED, Klug JL, Palmer TM (1996) Bottle or big-scale studies: how do we do ecology? Ecology $77: 681-685$

Jackson GA (1987) Simulating chemotaxis by marine microorganisms. Limnol Oceanogr 32:1253-1266

Jackson GA (1989) Simulation of bacterial attraction and adhesion to falling particles in an aquatic environment. Limnol Oceanogr 34:514-530

Jafeem BA (1996) Soil microcosms and the population biology of nematophagous fungi. Ecology 77.690-693

Jumars PA (1993) Concepts in biological oceanography: an interdisciplinary primer. Oxford Univ Press, New York

Kemp PF, Sherr BF, Sherr EB, Cole JJ (1993) Handbook of methods in aquatic microbial ecology. Lewis Publishers, Boca Raton, FL 
Kirchman DL, Keil RG, Wheeler PA (1990) Carbon limitation of ammonium uptake by heterotrophic bacteria in the subarctic Pacific. Limnol Oceanogr 35:1258-1266

Kroer N, Coffin RB (1992) Microbial trophic interactions in aquatic microcosms designed for testing genetically engineered microorganisms: a field comparison. Microb Ecol 23:143-157

Likens GE (1985) An experimental approach for the study of ecosystems. J Ecol 73:381-396

López NI, Duarte CM, Vallespiñós F, Romero J, Alcoverro T (1997) The effect of nutrient additions on bacterial activity in seagrass (Posidonia oceanica) sediments. J Exp Mar Biol Ecol (in press)

Mackas DL, Denman KL, Abbott MR (1985) Plankton patchiness: biology in the physical vernacular. Bull Mar Sci 37: 652-674

Marrasé C, Lim EL, Caron DA (1992) Seasonal and daily changes in bacteriovory in a coastal plankton community. Mar Ecol Prog Ser 82:281-289

Müller-Niklas G, Agis M, Herndl GJ (1996) Microscale distribution of bacterioplankton in relation to phytoplankton: results from 100-nl samples. Limnol Oceanogr 41: $1577-1582$

Mullin MM (1982) How can enclosing seawaters liberate biological oceanographers? In: Grice GD, Reeve MR (eds) Marine mesocosms. Biological and chemical research in experimental mesocosms. Springer-Verlag, New York, p $399-410$

Naeem S, Thompson LJ, Lawler SP, Lawton JH, Woodfin RM (1994) Declining biodiversity can alter ecosystem performance. Nature 368:734-737

Pace ML (1991) Comparative and experimental approaches to the study of microbial food webs. J Protozool 38:87-92

Pace ML, Cole JJ (1994) Comparative and experimental approaches to top-down and bottom-up regulation of bacteria. Microb Ecol 28:181-193

Pace ML, Cole JJ (1996) Regulation of bacteria by resources and predation tested in whole-lake experiments. Limnol Oceanogr 41:1448-1460

Parsons TR (1982) The future of controlled ecosystem enclosure experiments. In: Grice GD, Reeve MR (eds) Marine mesocosms. Biological and chemical research in experimental ecosystems. Springer-Verlag, New York, p 411-418

Responsible Subject Editor: T. F. Thingstad, Roskilde, Denmark
Peters RH (1991) A critique for ecology. Cambridge Univ Press, Cambridge

Platt JR (1964) Strong inference. Science 146:347--352

Pomeroy LR (1974) The ocean's food web, a changing paradigm. BioSci 24:499-504

Porter KG, Feig YS (1980) The use of DAPI for identification and enumeration of bacteria and blue-green algae. Limnol Oceanogr 25:943-948

Proctor LM, Fuhrman JA (1990) Viral mortality of marine bacteria and cyanobacteria. Nature 343:60-62

Redfield AC (1958) The inadequacy of experiments in marine biology. In: Buzzati-Traverso A (ed) Perspectives in marine biology. University of California Press, Berkeley, p 17-23

Schindler DW and 6 coauthors (1985) Long-term ecosystem stress: the effects of years of experimental acidification on a small lake. Science 228:1395-1401

Schindler DW, Fee EJ (1974) Experimental lakes area: wholelake experiments in eutrophication. J Fish Res Bd Can 31: 937-953

Shiah FK, Ducklow HW (1994) Temperature and substrate regulation of bacterial abundance, production and specific growth rate in Chesapeake Bay, USA. Mar Ecol Prog Ser 103:297-308

Sieburth JMcN, Estep KW (1985) Precise and meaningful terminology in marine microbial ecology. Mar Microb Food Webs $1: 1-16$

Simon M, Azam F (1989) Protein content and protein synthesis rates of planktonic marine bacteria. Mar Ecol Prog Ser 51:201-213

Stewart-Oaten A, Bence JR, Osenberg CW (1992) Assessing effects of unreplicated perturbations: no simple solutions. Ecology 73:1396-1404

Tortell PD, Maldonado MT, Price NM (1996) The role of heterotrophic bacteria in iron-limited ocean ecosystems. Nature 383:330-332

Twiss MR, Campbell PGC (1995) Regeneration of trace metals from picoplankton by nanoflagellate grazing. Limnol Oceanogr 40:1418-1429

Valiela I (1995) Marine ecological processes, 2nd edn. Springer-Verlag, New York

Williams PJleB (1981) Incorporation of microheterotrophic processes into the classical paradigm of the planktonic food web. Kieler Meersforsch Sonderh 5:1-28

Manuscript received: September 10,1996

Revised version accepted: June 17, 1997 